This item was submitted to Loughborough's Research Repository by the author.

Items in Figshare are protected by copyright, with all rights reserved, unless otherwise indicated.

\title{
Identifying the major contributions to risk in phased missions
}

PLEASE CITE THE PUBLISHED VERSION

PUBLISHER

(C) Institute of Electrical and Electronics Engineers (IEEE)

LICENCE

CC BY-NC-ND 4.0

REPOSITORY RECORD

Andrews, J.D.. 2008. "Identifying the Major Contributions to Risk in Phased Missions". figshare. https://hdl.handle.net/2134/3841. 
This item was submitted to Loughborough's Institutional Repository (https://dspace.lboro.ac.uk/) by the author and is made available under the following Creative Commons Licence conditions.

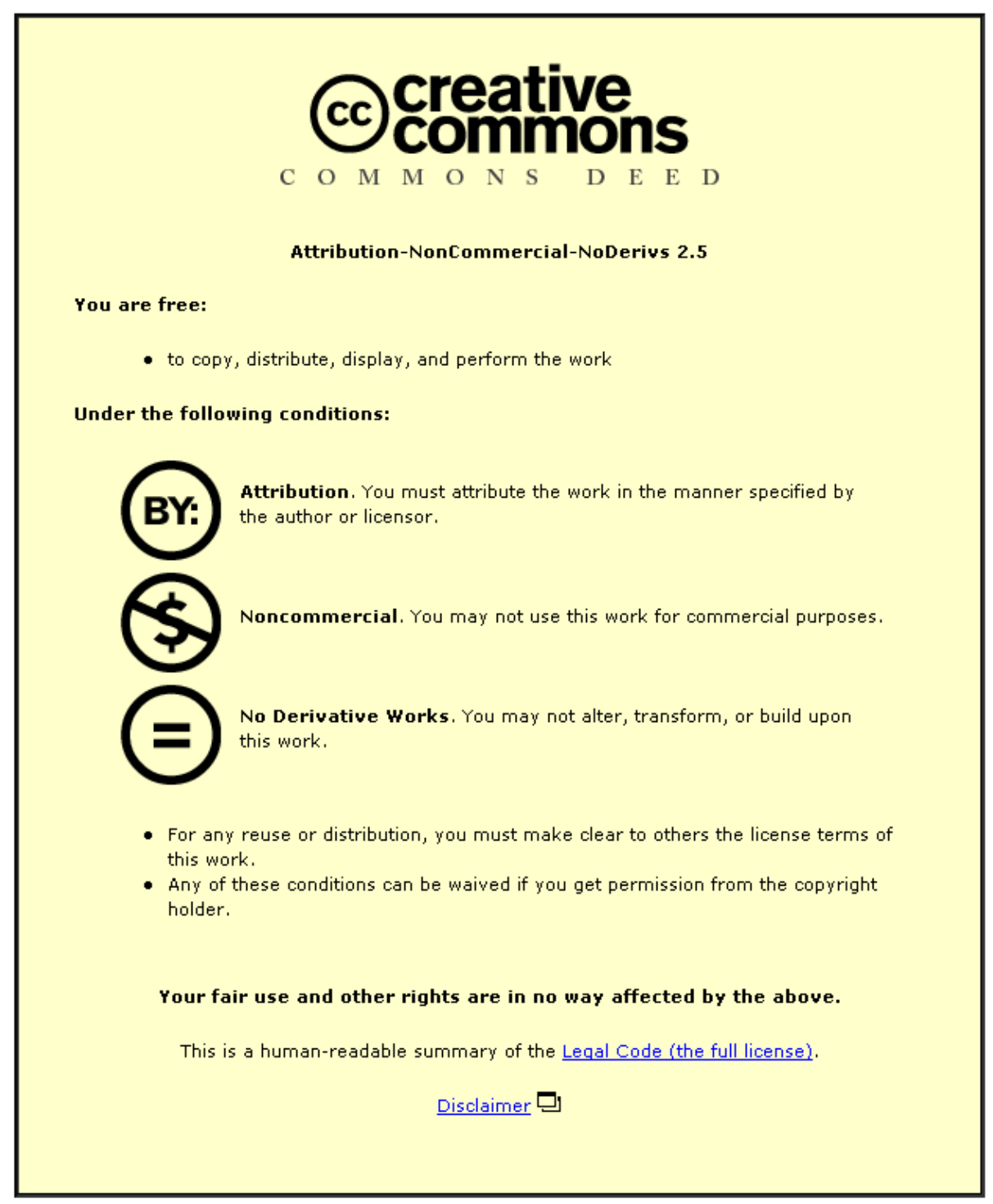

For the full text of this licence, please go to: http://creativecommons.org/licenses/by-nc-nd/2.5/ 


\title{
Identifying the Major Contributions to Risk in Phased Missions
}

\author{
John Andrews, Loughborough University
}

Key Words: phased missions, importance measures, mission unreliability, non-repairable systems

\section{SUMMARY \& CONCLUSIONS}

Many systems operate phased missions. The mission consists of a number of consecutive phases where the functional requirement of the system changes during each phase. A successful mission is the completion of each of the consecutive phases. For non-repairable systems, efficient analysis methods have recently been developed to predict the mission unreliability. In the event that the predicted performance falls below that which is required, modifications are made to improve the design. In conventional system failure analysis importance measures, which identify the contribution each component makes to the failure, can be used to identify the weaknesses. Importance measures relevant for phased mission applications are developed in this paper.

\section{INTRODUCTION}

The utilisation of many systems can be expressed in terms of missions which are split into a sequence of contiguous phases. Mission success is only achieved if each of the phases is successful and each phase is required to achieve a different objective and use different elements of the system. An obvious example of a phased mission is an aircraft flight. A successful flight will require the aircraft to taxi to the runway, take off, ascend to the required altitude, cruise, descend, land and taxi back to the terminal. Each of the phases in this sequence will require different sub-systems on the aircraft to function.

Component failures can occur in phases where their functionality is not required and remain unrevealed until needed later in the mission. For example, the landing gear may malfunction after the take-off phase. This will be carried through the subsequent phases until the landing gear is required in the landing phase when the failure will manifest itself and cause mission failure.

Difficulties in terms of the analysis of such situations occur due to three aspects:

i) it cannot be assumed that all components are fully functional at the start of each phase, even if it is an appropriate assumption at the start of the mission.

ii) failure in a particular phase needs to account for the successful completion of prior phases which will restrict the time period in which some component failures can occur to contribute to the phase failure under consideration.

iii) when the failure conditions for a phase have occurred prior to the system entering the phase, failure occurs at the point of transfer to the phase not when the component failures occur.

For a Risk Analysis of a phased mission the consequences of failure can also depend on which phase the failure occurs. Failure whilst taxiing to or from the terminal would be an inconvenience. Failure during flight would be catastrophic.

As with any system, phased mission or not, following a Risk Analysis the adequacy of the proposed design is appraised. In the event that the performance does not meet with the acceptance requirement, weaknesses in the design are identified and improvements made to rectify the deficiencies. In conventional system Risk Assessments, importance measures can be predicted which provide a numerical indicator of the significance that each component plays in the system failure. This paper develops an appropriate importance measure to identify the design weaknesses when the system operates as a phased mission.

\section{PHASED MISSION EXAMPLE}

A very simple example phased mission problem consisting of non-repairable components $\mathrm{A}, \mathrm{B}$ and $\mathrm{C}$ will be used to demonstrate the concepts presented. The phase failure fault trees are illustrated in Figure 1. The fault trees express the component failure conditions which will result in the failure of the phase. They could of course have occurred at any point of the mission up to and during the phase of concern. During phase 1 which lasts from $t_{0}$ until $t_{1}$ the failure of either A or B will cause the phase failure. Phase 2, lasting from $t_{1}$ until $t_{2}$ will fail if both components $A$ and $B$ have failed. The final phase will fail if component $\mathrm{C}$ is failed or if components $A$ and $B$ are failed and lasts from $t_{2}$ until $t_{3}$. If failure is avoided in all three phases the mission is successful and the probability of this is the mission reliability.

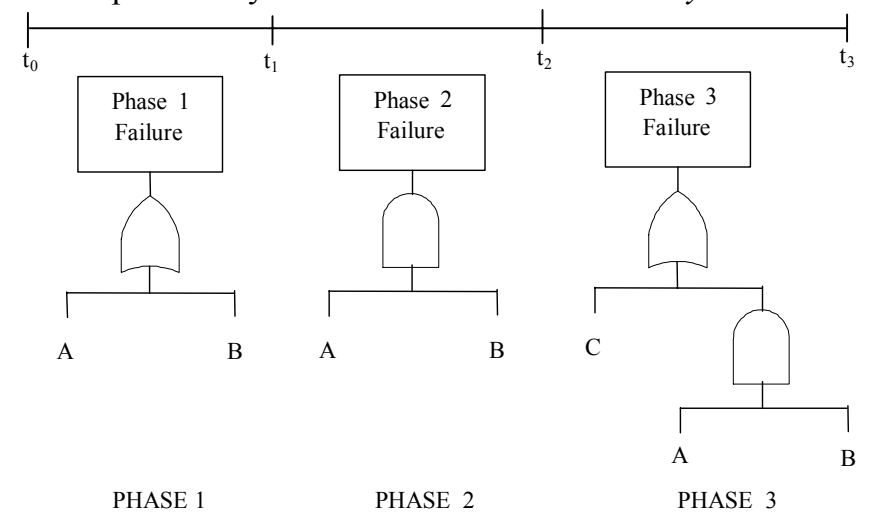

Figure 1. Phase Failure Causes for a Simple Phased Mission Example 


\section{PHASED MISSION RELIABILITY CALCULATIONS}

Fault Tree Analysis has been used to determine the phased mission unreliability for non-repairable systems. This topic was first addressed by Esary and Ziehms (ref 1). In 2004, La Band and Andrews presented an efficient phased mission analysis method using Binary Decision Diagrams (ref 2 ). The approach adopted was to calculate the probability of failure in each of the phases, $Q_{j}$, accounting for the successful operation of preceding phases. Mission unreliability, $\mathrm{Q}_{\mathrm{MISS}}$, is then obtained by summing the failure probability of each of the $\mathrm{n}$ phases, as shown in $\mathrm{Eq}(1)$.

$$
Q_{\text {MISS }}=\sum_{j=1}^{n} Q_{j}
$$

\subsection{Phase Failure Fault Trees}

For each phase, $\mathrm{j}$, a phase failure fault tree is constructed. This expresses the causes of failure in the phase under analysis, accounting for the success in the previous $1, \ldots, j-1$ phases, and also the conditions for failure in the jth phase. This fault tree structure is illustrated in Figure 2.

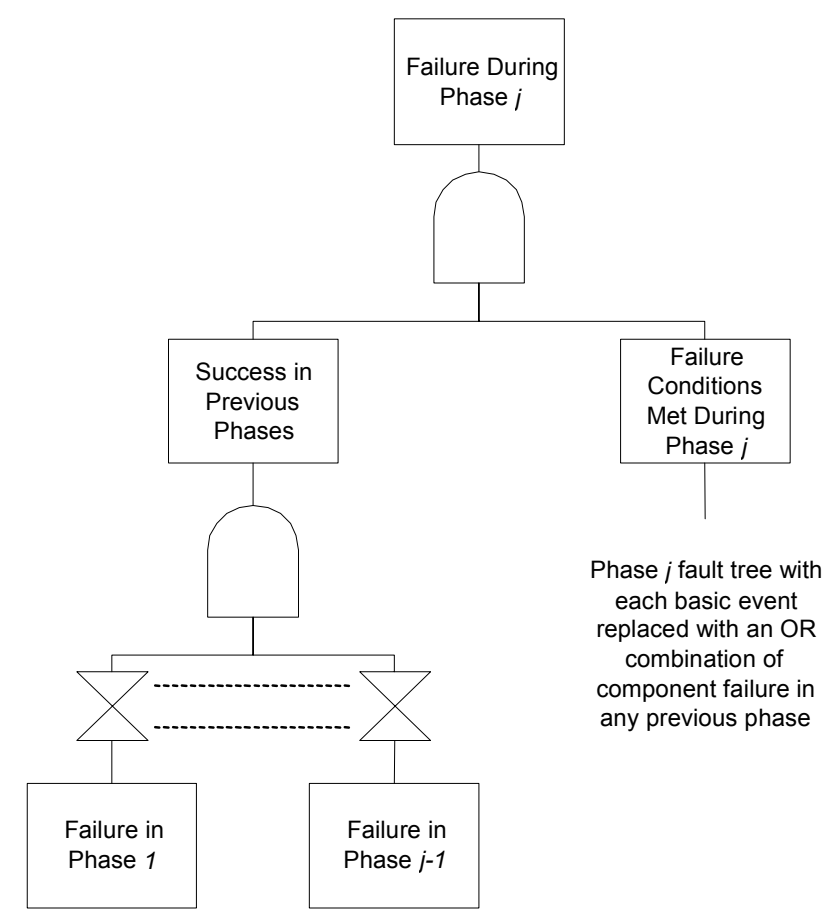

Figure 2. Phase j Failure Fault Tree Structure

It should be noted that in developing this fault tree for any component failure event, $A$, to be in the failed state in phase $j$, the failure could have occurred in the jth phase or any of the preceding phases and so the basic event $A$ in the phase $\mathrm{j}$ failure fault tree is replaced by $\mathrm{A}_{1}+\mathrm{A}_{2}+\ldots . .+\mathrm{A}_{\mathrm{j}}$ (where + is logical OR). As an example the fault tree structure for failure in phase 2 for the example illustrated in Figure 1 is given in Figure 3.

\subsection{Phase Failure Modes/Failure Probabilities}

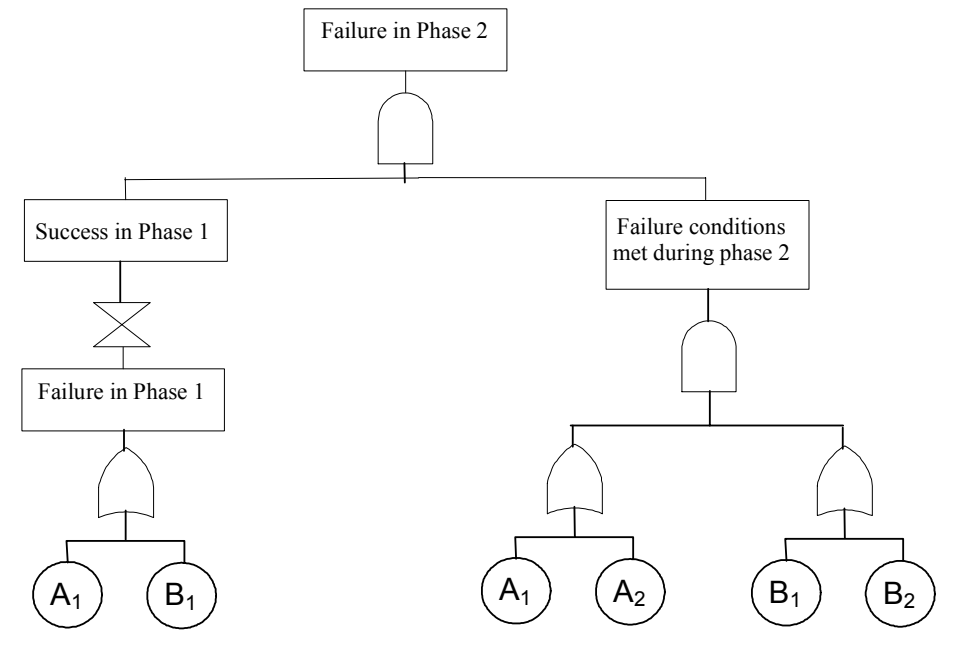

Figure 3. Phase 2 Failure Fault Tree Structure

Boolean reduction of the phase failure fault trees wilproduce the phase failure modes. Consider the fault tree illustrated in Figure 3. Eq. (2) establishes a Boolean expression $\left(\mathrm{TOP}_{2}\right)$ for the fault tree giving the phase 2 failure modes (the negated term represents the conditions for success in phase 1 and the remainder of the expression is the failure conditions for phase 2):

$$
\begin{aligned}
\text {TOP}_{2} & =\overline{A_{1}} \overline{B_{1}}\left(A_{12} \cdot B_{12}\right) \\
& =A_{2} B_{2}
\end{aligned}
$$

where: $A_{j}$ is the failure of component $\mathrm{A}$ in phase $\mathrm{j}, \overline{A_{j}}$ is the event that $\mathrm{A}$ works throughout phase $\mathrm{j}$. The notations can be extended to give the component conditions through a range of phases $\mathrm{i}$ to $\mathrm{j}$ using $A_{i j}$ and $\overline{A_{i j}}$ for failed and functioning respectively. More details of the phase algebra to manipulate the top event expression can be found in reference 2 . The probability of $\mathrm{TOP}_{2}$ produces the phase 2 failure probability, $\mathrm{Q}_{2}$ as shown in Eq. 3:

$$
Q_{2}=q_{A_{2}} \cdot q_{B_{2}}
$$

In this case, the probability of phase failure is only dependent on component failure events. When success conditions are also included, the probability function is formed using $p$ to denote the probability of success events and $q$ the probability of failure events, as for non-coherent systems. References 3 and 4 provide more details on forming the probability function.

Considering phases 1 and 3 in the same way gives Eq. 4:

$$
\begin{gathered}
T O P_{1}=A_{1}+B_{1} \\
Q_{1}=q_{A_{1}}+q_{B_{1}}-q_{A_{1}} \cdot q_{B_{1}} \\
T O P_{3}=\bar{A}_{1} \bar{B}_{1} \frac{\left.\overline{(} A_{12}+B_{12}\right)}{\left(A_{13} \cdot B_{13}+C_{13}\right)} \\
=A_{3} B_{23}+\bar{A}_{12} \bar{B}_{1} C_{13}+A_{23} B_{3}+\bar{A}_{1} \bar{B}_{12} C_{13} \\
Q_{3}=q_{A_{3}} q_{B_{23}}+p_{A_{12}} p_{B_{1}} q_{C_{13}}+q_{A_{23}} q_{B_{3}}+p_{A_{1}} p_{B_{12}} q_{C_{13}} \\
-\left[q_{A_{3}} q_{B_{23}} q_{C_{13}}+q_{A_{3}} q_{B_{3}}+p_{A_{12}} p_{B_{12}} q_{C_{13}}+q_{A_{23}} q_{B_{3}} q_{C_{13}}\right] \\
+q_{A_{3}} q_{B_{3}} q_{C_{13}}
\end{gathered}
$$




\section{CRITICAL SYSTEM STATES}

In order to develop component importance measures we require the concept of a critical system state. For a nonphased mission this is defined as:

A critical system state for component $i$ is a state of the remaining (n-1) components in the system such that the failure of component $i$ will cause the system to make a transition from the working to the failed state.

This definition is appropriate for either non-phased missions or the first phase of a phased mission. As an example, consider the criticality of component $\mathrm{A}$ in phase 1 of the example illustrated in Figure 1. All combinations of the states (working or failed) for the remaining components (B and $\mathrm{C}$ ) are listed in Table 1 . Phase 1 will fail if either component B fails or A fails. Since we are looking at the criticality for $\mathrm{A}$ it must be assumed that $\mathrm{A}$ is functioning and we test to see if its failure will fail a working system. If component $\mathrm{B}$ and $\mathrm{C}$ both work, or if $\mathrm{B}$ works and $\mathrm{C}$ fails, the failure of $\mathrm{A}$ will fail the system. Therefore, these states are critical for A. For the last 2 states listed in the table, B has failed and therefore the system has failed and the failure of component $\mathrm{A}$ has no effect on system performance. The probability of each critical state is given in the third column.

\begin{tabular}{|c|c|c|}
\hline $\begin{array}{c}\text { Other } \\
\text { Component States }\end{array}$ & Critical for A & Probability \\
\hline$\left(., \overline{\mathrm{B}}_{1}, \overline{\mathrm{C}}_{1}\right)$ & Yes & $\left(1-q_{B_{1}}\right)\left(1-q_{C_{1}}\right)$ \\
\hline$\left(., \overline{\mathrm{B}}_{1}, \mathrm{C}_{1}\right)$ & Yes & $\left(1-q_{B_{1}}\right) q_{C_{1}}$ \\
\hline$\left(., \mathrm{B}_{1}, \overline{\mathrm{C}}_{1}\right)$ & No & \\
\hline$\left(., \mathrm{B}_{1}, \mathrm{C}_{1}\right)$ & No & \\
\hline
\end{tabular}

Table 1. Criticality of component A in phase 1

\subsection{Criticality Function}

This is also known as Birnbaum's measure of importance (ref 5) and whilst being an importance measure in its own right, it is also the basis of several other importance measures. The criticality function, $G_{i}$, for each component $i$ is defined as the probability that the system is in a critical state for component i. From Table 1 it can be seen that (Eq. 5):

$$
\begin{aligned}
G_{A} & =\left(1-q_{B_{1}}\right)\left(1-q_{C_{1}}\right)+q_{C_{1}}\left(1-q_{B_{1}}\right) \\
& =\left(1-q_{B_{1}}\right)
\end{aligned}
$$

Constructing a similar table for the other components gives (Eq. 6):

$$
\begin{aligned}
G_{B} & =\left(1-q_{A_{1}}\right) \\
G_{C} & =0
\end{aligned}
$$

\section{CRITICAL PHASE STATES}

For multi-phased missions the possible component states in any phase are dependent upon which failures have occurred during all of the preceding states up to and including phase $\mathrm{j}$.

A critical state for component $i$ in phase $j$ is a state of the remaining components through the previous and current phases such that the system is working in phase $\mathrm{j}$ and the failure of component $i$ will then cause phase (and mission) failure.

For this to happen:

i) all phases up to phase $\mathrm{j}$ must have completed successfully, and

ii) component $i$ is in the working state at the start of phase $j$.

If we consider a component A operating over two phases we need to identify all possible alternatives for this component which will enable us to determine its state and the probability of it being in these states. Therefore we need to consider $\mathrm{A}_{1}$ and $\mathrm{A}_{2}$ (failure in phases 1 or 2 respectively) or $\overline{A_{12}}$ where the component survives without failure over both phases.

As an example consider the critical states for component A in phase 2 of the simple phased mission example illustrated in Figure 1. The alternative states for the remaining components are listed in Table 2

\begin{tabular}{|c|c|c|c|}
\hline $\begin{array}{c}\text { Other } \\
\text { Component State }\end{array}$ & $\begin{array}{c}\text { Fails in } \\
\text { Phase 1 }\end{array}$ & $\begin{array}{c}\text { Critical for A } \\
\text { in Phase 2? }\end{array}$ & Probability \\
\hline$\left(., \overline{\mathrm{B}}_{12}, \overline{\mathrm{C}}_{12}\right)$ & No & No & \\
\hline$\left(., \mathrm{B}_{1}, \overline{\mathrm{C}}_{12}\right)$ & Yes & - & \\
\hline$\left(., \mathrm{B}_{2}, \overline{\mathrm{C}}_{12}\right)$ & No & Yes & $q_{B_{2}}\left(1-q_{C_{12}}\right)$ \\
\hline$\left(., \overline{\mathrm{B}}_{12}, \mathrm{C}_{1}\right)$ & No & No & \\
\hline$\left(., \overline{\mathrm{B}}_{12}, \mathrm{C}_{2}\right)$ & No & No & \\
\hline$\left(., \mathrm{B}_{1}, \mathrm{C}_{1}\right)$ & Yes & - & \\
\hline$\left(., \mathrm{B}_{1}, \mathrm{C}_{2}\right)$ & Yes & - & \\
\hline$\left(., \mathrm{B}_{2}, \mathrm{C}_{1}\right)$ & No & Yes & $q_{B_{2}} q_{C_{1}}$ \\
\hline$\left(., \mathrm{B}_{2}, \mathrm{C}_{2}\right)$ & No & Yes & $q_{B_{2}} q_{C_{2}}$ \\
\hline
\end{tabular}

Table 2. Critical States for Component A in Phase 2

The first entry in Table 2 has components B and C functioning throughout phases 1 and 2 . The next four entries consider a single failure of $\mathrm{B}$ or $\mathrm{C}$ in either of the two phases.

Finally the last four entries consider all possible orderings where both of components $\mathrm{B}$ and $\mathrm{C}$ fail at some point in the first two phases. The second column indicates those states which survive beyond phase 1 . The three entries where component $\mathrm{B}$ fails in phase 1 result in phase 1 failure and therefore cannot contribute to what happens in phase 2. Of those states surviving phase 1 their criticality for component A in phase 2 is then considered and entered into column 3 of table 2. As the phase 2 failure requirement is that $\mathrm{A}$ and $\mathrm{B}$ are both failed the three critical phase states are those entered on rows 3, 8 and 9 (where $\mathrm{B}$ has failed in phase 2). The probability of each of these critical states is given in column 4 . 


\subsection{Phase Criticality Function}

The phase criticality function for component $i$ in phase $j$ is defined as the probability that the system is in a critical state for component $i$ in phase $j, G_{i, j}$. For component $A$ in phase 2 this is (Eq. 7):

$$
\begin{aligned}
G_{A, 2} & =q_{B_{2}}\left(1-q_{C_{12}}\right)+q_{B_{2}} q_{C_{1}}+q_{B_{2}} q_{C_{2}} \\
& =q_{B_{2}}
\end{aligned}
$$

By the same process (Eq. 8):

$$
\begin{aligned}
G_{B, 2} & =q_{A_{2}} \\
G_{C, 2} & =0
\end{aligned}
$$

Using the same approach the phase 3 criticality functions for each component are found to be (Eq. 9):

$$
\begin{aligned}
G_{A, 3} & =q_{B_{23}}\left(1-q_{C_{13}}\right) \\
G_{B, 3} & =q_{A_{23}}\left(1-q_{C_{13}}\right) \\
G_{C, 3} & =1-q_{A_{1}}-q_{B_{1}}+q_{A_{1}} q_{B_{1}}-q_{A_{3}} q_{B_{2}}-q_{A_{3}} q_{B_{3}}-q_{A_{2}} q_{B_{2}} \\
& -q_{A_{2}} q_{B_{3}}
\end{aligned}
$$

\section{EFFICIENT CALCULATION OF THE PHASE CRITICALITY FUNCTION}

The tabular approach presented above to calculate the criticality function, whilst demonstrating the philosophy of the method, becomes impractical due the size of the table as the number of components and the number of phases increases. However a simpler more efficient approach exists which is based on the phase failure likelihood function. From these the phase criticality function can be produced by (Eq 10):

$$
G_{i, j}=\frac{\partial Q_{j}}{\partial q_{i_{j}}}
$$

This can be demonstrated using the simple phased mission example.

For phase 1 (Eq 11):

$$
\begin{aligned}
& Q_{1}=q_{A_{1}}+q_{B_{1}}-q_{A_{1}} q_{B_{1}} \\
& G_{A, 1}=\frac{\partial Q_{1}}{\partial q_{A_{1}}}=1-q_{B_{1}} \quad G_{B, 1}=\frac{\partial Q_{1}}{\partial q_{B_{1}}}=1-q_{A_{1}} \quad \mathrm{G}_{\mathrm{C}, 1}=0
\end{aligned}
$$

For phase 2 (Eq 12):

$$
\begin{aligned}
& Q_{2}=q_{A_{2}} q_{B_{2}} \\
& G_{A, 2}=\frac{\partial Q_{2}}{\partial q_{A_{2}}}=q_{B_{2}} \quad G_{B, 2}=\frac{\partial Q_{2}}{\partial q_{B_{2}}}=q_{A_{2}} \quad \mathrm{G}_{\mathrm{C}, 2}=0
\end{aligned}
$$

For phase 3 (Eq. 13):

$$
\begin{aligned}
Q_{3} & =q_{A_{3}} q_{B_{23}}+p_{A_{12}} p_{B_{1}} q_{C_{13}}+q_{A_{23}} q_{B_{3}}+p_{A_{1}} p_{B_{12}} q_{C_{13}} \\
& -\left[q_{A_{3}} q_{B_{23}} q_{C_{13}}+q_{A_{3}} q_{B_{3}}+p_{A_{12}} p_{B_{12}} q_{C_{13}}+q_{A_{23}} q_{B_{3}} q_{C_{13}}\right] \\
& +q_{A_{3}} q_{B_{3}} q_{C_{13}} \\
G_{A, 3} & =\frac{\partial Q_{3}}{\partial q_{A_{3}}}=q_{B_{23}}\left(1-q_{C_{13}}\right) \quad G_{B, 3}=\frac{\partial Q_{3}}{\partial q_{B_{3}}}=q_{A_{23}}\left(1-q_{C_{13}}\right) \\
\mathrm{G}_{\mathrm{C}, 3} & =\frac{\partial Q_{3}}{\partial q_{C_{3}}}=1-q_{A_{1}}-q_{B_{1}}+q_{A_{1}} q_{B_{1}}-q_{A_{2}} q_{B_{23}}-q_{A_{23}} q_{B_{2}}
\end{aligned}
$$
table.

\section{PHASE CRITICALITY IMPORTANCE MEASURES}

The Phase Criticality Function is an importance measure in its own right and indicates the susceptibility of the system to the failure of each component in each phase. However, as can be seen, a component's criticality function it is not dependent upon its own failure probability and is used to form more informative measures to indicate the contribution that a component makes to the phase and mission failure.

For a system to fail it needs to be in a critical condition for any of the i components and also the (ith) component fails. If this contribution is then divided by the system failure probability we have the proportion of times that the failure of component $i$ causes system failure, i.e., a measure of the contribution that component i makes to system failure.

Putting the above concept into the context of a phased mission two scenarios are presented that can result in phase and mission failure:

1. For any phase the system can be in a critical state for a component $i$ in phase $j$ and component $i$ then fails during the phase causing phase failure. (Phase importance)

2. Alternatively the failure conditions for phase $\mathrm{j}$ may exist prior to the mission entering phase $\mathrm{j}$ and phase failure occurs on transition to phase j. (Transition Importance).

For a component $i$ to contribute to transition failure the system is in a critical state for component $i$ with respect to phase $\mathrm{j}$ in a phase prior to phase $\mathrm{j}$ and component $\mathrm{i}$ also fails prior to this phase.

These scenarios give rise to two measures of component importance for each mission phase:

Phase Component Importance for component $\mathrm{i}$ in phase $\mathrm{j}$ (Eq. 14)

$$
I_{i, j}^{P}=\frac{G_{i, j} q_{i_{j}}}{Q_{j}}=\frac{\frac{\partial Q_{j}}{\partial q_{i_{j}}} q_{i_{j}}}{Q_{j}}
$$

All parameters required in this importance measure have been established in the previous sections of the paper.

Phase Transition Importance for component $\mathrm{i}$ in phase $\mathrm{j}$

$\mathrm{Q}_{\mathrm{j}}$ is the probability that the conditions for failure in phase $\mathrm{j}$ occur. It accounts for the probability of failure during the phase and on transition into the phase. To establish the probability of failure on transition to the phase the logic equations for the causes of phase failure need to remove any of the failure events which occur in phase $\mathrm{j}$. This is equivalent to establishing the causes of phase failure in phase $\mathrm{j}$ in the $1 \ldots \mathrm{j}-1$ phases prior to phase $\mathrm{j}$ and can be achieved by modifying the right hand box from the top event on the fault tree in Figure 2 to be "failure conditions met prior to phase $\mathrm{j}$.

There is obviously no failure on transfer into phase 1 as all components are assumed to be functioning at this point in time. For failure on entry to phase 2 the logic function for phase 2 failure, and phase 1 success, (equation 2) is modified to remove phase 2 failure events giving (Eq. 15):

$$
\text { Top }_{2}^{T}=\bar{A}_{1} \bar{B}_{1}\left(A_{1} B_{1}\right)=0 \text { giving } \mathrm{Q}_{2}^{\mathrm{T}}=0
$$

Similarly for phase 3 (Eq. 16): 


$$
\begin{aligned}
\operatorname{Top}_{3}^{T} & =\bar{A}_{1} \bar{B}_{1}\left(\overline{A_{12}+B_{12}}\right)\left(A_{12} B_{12}+C_{12}\right) \\
& =\bar{A}_{12} \bar{B}_{1} C_{12}+\bar{A}_{1} \bar{B}_{12} C_{12}
\end{aligned}
$$

giving (Eq. 17):

$$
Q_{3}^{T}=p_{A_{12}} p_{B_{1}} q_{C_{12}}+p_{A_{1}} p_{B_{12}} q_{C_{12}}-p_{A_{12}} p_{B_{12}} q_{C_{12}}
$$

The phase criticality function for phase $\mathrm{j}$ transition failure due to the failure of component $i$ in a phase $k$ prior to $j, G_{i, j, k}^{T}$ is (Eq. 18):

$$
G_{i, j, k}^{T}=\frac{\partial Q_{j}^{T}}{\partial q_{i_{k}}}
$$

Phase transition failure requires that the failure conditions have occurred for phase $\mathrm{j}$ in some phase, $\mathrm{k}$, prior to phase $\mathrm{j}$ but these conditions have not caused previous phase failure. This importance measure is the failure contribution that component $i$ makes to the transition failure of phase $j$ as a proportion of the total phase failure probability i.e., (Eq. 19):

$$
I_{i, j}^{T}=\frac{\left(\sum_{k=1}^{j-1} G_{i, j, k}^{T} q_{i_{k}}\right)}{Q_{j}}=\frac{\left(\sum_{k=1}^{j-1} \frac{\partial Q_{j}^{T}}{\partial q_{i_{k}}} q_{i_{k}}\right)}{Q_{j}}
$$

\section{PHASED MISSION IMPORTANCE CONTRIBUTIONS}

The total importance contribution of component i failure in phase $\mathrm{j}$ is (Eq. 20):

$$
I_{i, j}=I_{i, j}^{P}+I_{i, j}^{T}
$$

A measure to indicate the total contribution made by a component $i$ to the whole mission failure of the system is (Eq. 21):

$$
I_{i}=\frac{\sum_{\substack{\text { all } \\ j}}\left\{\frac{\partial Q_{j}}{\partial q_{i_{j}}} q_{i_{j}}+\left(\sum_{k=1}^{j-1} \frac{\partial Q_{j}^{T}}{\partial q_{i_{k}}} q_{i_{k}}\right)\right\}}{Q_{\text {Miss }}}
$$

\section{SYSTEM EXAMPLE}

\subsection{Phase Component Importance}

As an example consider the contribution that the components make to phase 3 of the simple example illustrated in Figure 1. From equation 13 substituted in to equation 14 gives (Eq. 22):

$$
\begin{gathered}
I_{A, 3}^{P}=\frac{G_{A, 3} q_{A_{3}}}{Q_{3}}=\frac{q_{B_{23}}\left(1-q_{C_{13}}\right) q_{A_{3}}}{Q_{3}} \\
I_{B, 3}^{P}=\frac{G_{B, 3} q_{B_{3}}}{Q_{3}}=\frac{q_{A_{23}}\left(1-q_{C_{13}}\right) q_{B_{3}}}{Q_{3}} \\
I_{C, 3}^{P}=\frac{G_{C, 3} q_{C_{3}}}{Q_{3}} \\
=\frac{\left[1-q_{A_{1}}-q_{B_{1}}+q_{A_{1}} q_{B_{1}}-q_{A_{2}} q_{B_{23}}-q_{A_{3}} q_{B_{23}}\right] q_{C_{3}}}{Q_{3}}
\end{gathered}
$$

\subsection{Phase Transition Importance}

$$
\begin{gathered}
\frac{\partial Q_{3}^{T}}{\partial q_{A_{i}}}=\frac{\partial Q_{3}^{T}}{\partial q_{B_{i}}}=0 \quad \mathrm{i}=1,2 \\
\frac{\partial Q_{3}^{T}}{\partial q_{C_{1}}}=\frac{\partial Q_{3}^{T}}{\partial q_{C_{2}}}=1-q_{A_{1}}-q_{B_{1}}+q_{A_{1}} q_{B_{1}}-q_{A_{2}} q_{B_{2}}
\end{gathered}
$$

Giving:

$$
\begin{aligned}
& I_{A, 3}^{T}=I_{B, 3}^{T}=0 \\
& I_{C, 3}^{T}=\frac{\left(1-q_{A_{1}}-q_{B_{1}}+q_{A_{1}} q_{B_{1}}-q_{A_{2}} q_{B_{2}}\right) q_{C_{12}}}{Q_{3}}
\end{aligned}
$$

\subsection{Example Importance Measures}

If the component failure probabilities are as given in Table 3, the system importance measures are given in Table 4 .

\begin{tabular}{|c|c|c|c|}
\hline COMPONENT & PHASE & PHASE & PHASE \\
& $\mathbf{1}$ & $\mathbf{2}$ & $\mathbf{3}$ \\
\hline $\mathrm{A}$ & 0.4 & 0.3 & 0.1 \\
\hline $\mathrm{B}$ & 0.2 & 0.1 & 0.05 \\
\hline $\mathrm{C}$ & 0.1 & 0.075 & 0.05 \\
\hline
\end{tabular}

Table 3. Component Phase Failure Data

In terms of the system performance:

Phase failure probabilities: $\mathrm{Q}_{1}=0.52, \mathrm{Q}_{1}=0.03, \mathrm{Q}_{1}=0.1245$ Mission failure probability: $\mathrm{Q}_{\mathrm{MISS}}=0.6745$

\begin{tabular}{|l|c|c|c|}
\hline \multicolumn{1}{|c|}{ Component } & A & B & C \\
\hline In Phase 1 Import & 0.615 & 0.231 & 0.0 \\
\hline In Phase 2 Import & 1.0 & 1.0 & 0.0 \\
\hline Trans to Phase 2 Import & 0.0 & 0.0 & 0.0 \\
\hline In Phase 3 Import & 0.093 & 0.125 & 0.159 \\
\hline Trans to Phase 3 Import & 0.0 & 0.0 & 0.6325 \\
\hline Total Mission Import & 0.536 & 0.245 & 0.146 \\
\hline
\end{tabular}

Table 4. Component Phase and Mission Importance Values

From Table 4 it can be seen that in phase 1 component A contributes most to the in-phase failure. Components A and B contribute equally to in-phase failure of phase 2 and phase 3 has contributions from all components with $\mathrm{C}, \mathrm{B}, \mathrm{A}$ representing the order of significance. However the large contribution to the failure in phase 3 is on transition into phase 3 this particular contribution all comes from component $\mathrm{C}$.

Over the entire mission $\mathrm{A}, \mathrm{B}$ and $\mathrm{C}$ contribute in that order and the largest improvement in the mission reliability could be obtained by focussing on improving the reliability of component A.

\section{REFERENCES}

1. J. D. Esary, H. Ziehms, "Reliability of Phased Missions", Reliability and Fault Tree Analysis, 1975, pp213-236 (Society for Industrial Applied mathematics, Philadelphia, Pennsylvania).

2. R. La Band, J. D. Andrews, "Phased Mission Modelling 
using Fault Tree Analysis", Proc of the IMechE, Vol 218, Part E, Process Mechanical Engineering, 2004, pp83-91.

3. Henley, Inagaki, "Probabilistic evaluation of prime implicants and top events for non-coherent systems", IEEE Transactions on Reliability, vol. R-29, No.5, Dec 1980.

4. J. D. Andrews, S. Beeson, "Birnbaum's Measure of Importance for Non-coherent Systems", IEEE Transactions on Reliability, Vol 52, No 2 June 2003, pp213-220.

5. Z.W. Birnbaum, "On the importance of different components in a multi-component system", Multivariate Analysis 11, P.R.Krishnaiah, ed., Academic Press, 1969

\section{BIOGRAPHY}

Professor John Andrews

Department of Aeronautical and Automotive Engineering Stewart Miller Building

Loughborough University

Loughborough

Leicestershire, LE11 3TU England

J.D.Andrews@lboro.ac.uk
John Andrews is Professor of Systems Reliability in the Department of Aeronautical and Automotive Engineering at Loughborough University, UK. He recently transferred to this department from the Mathematical Sciences Department where he had worked since he joined Loughborough University in 1989. The prime focus of his research has been on methods for predicting system risk and reliability in terms of the component failure probabilities and a representation of the system structure. Much of this work has concentrated on the Fault Tree technique and the use of the Binary Decision Diagrams (BDDs) as an efficient and accurate solution method. He is the author of around 100 research papers on this topic and is joint author, with Bob Moss, of a text book, Reliability and Risk Assessment, now in its second edition, published by ASME. John is a member of the Safety and Reliability Group of the Institution of Mechanical Engineers (IMechE) and is Editor-in-Chief of Part O, the Journal of Risk and Reliability, of the IMechE Proceedings. John was Chairman of the Organising Committee for the $16^{\mathrm{TH}}$ ARTS (Advances in Reliability Technology Symposium) held at Loughborough University in April 2005. 